\title{
Efficacy of Mechanical Insufflation-Exsufflation in Extubating Unweanable Subjects With Restrictive Pulmonary Disorders
}

\author{
John R Bach MD, Diane M Sinquee MD, Louis R Saporito RRT, Amanda L Botticello PhD
}

\begin{abstract}
BACKGROUND: Subjects who do not pass ventilator weaning parameters but whose ambient air oxyhemoglobin saturation can be normalized by mechanical insufflation-exsufflation (MIE) can be extubated to continuous noninvasive ventilatory support (CNVS) with MIE used to maintain extubation. Our aim was to study MIE-associated changes in breathing tolerance, pulse oximetry, and vital capacity (VC) for consecutive unweanable subjects. METHODS: A retrospective chart review was performed for consecutively referred intubated subjects with single-organ (respiratory muscle) failure. At presentation, $\mathrm{CO}_{2}$ was normalized by adjusting ventilator settings and $\mathrm{VC}$ was measured (point 1). Then, MIE was used via the tube up to every $h$ until oximetry remained $\geq 95 \%$ on ambient air and VC was remeasured (point 2) immediately before extubation. Subjects who could not meet ventilator weaning criteria and had no ventilator-free breathing ability upon extubation to CNVS were enrolled. Post-extubation, the MIE was used to maintain oximetry $\geq 95 \%$ in room air. VC and breathing tolerance were remeasured within 3 weeks (point 3). RESULTS: Ninetyseven of 98 subjects were successfully extubated despite 45 having been CNVS-dependent for 4 months to $18 \mathrm{y}$ before being intubated. Sixty-nine of the 98 were intubated for $24.9 \pm 22$ (range 1-158) $d$ and failed 0-6 (mean 1.7) extubation attempts before being transferred and successfully extubated in $2.24 \pm 1.78$ (range $<1-8)$ d to CNVS. VC increased by $270 \%(P<.001)$ from points 1 to 3. Weaning from CNVS to part-time NVS was achieved by all 52 subjects who had not been CNVS-dependent before intubation. One subject underwent tracheotomy. CONCLUSIONS: Many unweanable subjects can be extubated to CNVS and MIE. The latter can normalize $\mathrm{O}_{2}$ saturation, increase VC, and facilitate extubation. Key words: Duchenne muscular dystrophy; noninvasive ventilation; mechanical insufflation-exsufflation; neuromuscular disease; spinal cord injury; respiratory. [Respir Care 2015;60(4):477-483. (C) 2015 Daedalus Enterprises]
\end{abstract}

\section{Introduction}

Complications of invasive mechanical ventilation via tracheotomy include an $8-65 \%^{1}$ incidence of tracheal stenosis, ${ }^{2}$ tracheoesophageal, ${ }^{3,4}$ and tracheopulmonary-subcutaneous fistulae, increased food aspiration, ${ }^{5}$ hemorrhage, chronic purulent bronchitis, granuloma formation, and sepsis from paranasal sinusitis. ${ }^{6,7}$ Vocal cord paralysis, laryngeal strictures, hypopharyngeal muscle dysfunction, and airway collapse can occur. ${ }^{8,9}$ Tracheotomy was shown to

Dr Bach and Mr Saporito are affiliated with the Department of Physical Medicine and Rehabilitation, Rutgers New Jersey Medical School, University Hospital, Newark, New Jersey; Dr Sinquee is affiliated with the Department of Pediatrics, Rutgers New Jersey Medical School, University Hospital, Newark, New Jersey; Dr Botticello is affiliated with the Department of Physical Medicine and Rehabilitation, Rutgers New Jersey Medical School, Kessler Foundation, West Orange, New Jersey. exacerbate endotracheal tube-associated laryngeal damage and increase the risk of laryngeal stenosis, ${ }^{10}$ so it may be preferable to maintain intubation longer when successful extubation can be anticipated. ${ }^{11}$ Tracheotomy can also increase dependence on mechanical ventilation. ${ }^{12}$

Liberating subjects from invasive ventilation, therefore, has the potential to decrease hospitalization rates, ${ }^{13}$ lengths of stay, ${ }^{14}$ cost, ${ }^{15,16}$ and long-term morbidity; to facilitate

\footnotetext{
Dr Bach has disclosed a relationship with Philips Respironics. The other authors have disclosed no conflicts of interest.

Correspondence: John R Bach MD, Department of Physical Medicine and Rehabilitation, University Hospital B-403, 150 Bergen Street, Newark, NJ 07103. E-mail: bachjr@njms.rutgers.edu.
}

DOI: $10.4187 /$ respcare.03584 
ventilator weaning; and to improve quality of life. ${ }^{17} \mathrm{How}-$ ever, patients with primarily respiratory muscle dysfunction who fail typical ventilator weaning parameters and are unable to pass spontaneous breathing trials (SBTs) conventionally undergo tracheotomy.

\section{See the Related Editorial on Page 621}

Extubation to even continuous or bi-level positive airway pressure (PAP) using low spans (inspiratory minus expiratory PAP less than $10 \mathrm{~cm} \mathrm{H}_{2} \mathrm{O}$ ) is inadequate for subjects with little or no vital capacity (VC) who need full setting ventilatory support. In addition, with invasive airway suctioning usually missing the left airways, extubation attempts can fail due to airway secretion encumbrance. In 2010, we reported that 155 of 157 intubated subjects who could not pass any SBTs or breathe without full ventilatory support post-extubation were successfully extubated to continuous noninvasive ventilatory support (CNVS). Eighty-three of these subjects were transferred to our hospital for extubation after being intubated for up to $80 \mathrm{~d}$ and failing up to 4 conventional extubation attempts. After using MIE via the translaryngeal tubes, ambient air oxygen saturation as measured by pulse oximetry $\left(\mathrm{S}_{\mathrm{pO}_{2}}\right)$ normalized at $95 \%$ or greater, and the subjects were then extubated to CNVS with MIE used up to every $30 \mathrm{~min}$ post-extubation. ${ }^{18}$ In 1990 and 1991, we also reported decanulation of unweanable high-level spinal cord injured subjects who were transitioned from continuous tracheostomy mechanical ventilation to CNVS. ${ }^{19,20}$ Most of these, and other decanulated subjects whose post-decanulation VCs increased to over $250 \mathrm{~mL}$, then weaned themselves to part-time NVS. ${ }^{19-21}$

Early research from 1954 reported VC increases of 15$42 \%$ in 67 subjects with obstructive dyspnea immediately following the expulsion of airway secretions by using MIE. ${ }^{22}$ In 1993, we reported normalization of $\mathrm{S}_{\mathrm{pO}_{2}}$ along with increases in $\mathrm{VC}$ of $15-400 \%$ (mean 55\%) by using MIE to eliminate airway mucus during chest infections for out-patients with neuromuscular disorders (NMDs). ${ }^{23}$ As $\mathrm{VC}$ increased with aggressive airway clearance, most subjects whose VCs exceeded $250 \mathrm{~mL}$, including 155 subjects in the 2010 study, also weaned to part-time NVS. In most cases, weaning was accomplished at home after discharge. Thus, it was incumbent on our respiratory therapists to perform MIE via the translaryngeal tubes and then to train the family to continue its use up to every $30 \mathrm{~min}$ immediately post-extubation.

The purpose of this study is to describe the changes in $\mathrm{VC}, \mathrm{S}_{\mathrm{pO}_{2}}$, and breathing tolerance associated with MIE use in preparing intubated ventilator unweanable subjects for successful extubations.

\section{QUICK LOOK}

\section{Current knowledge}

Mechanical insufflation-exsufflation (MIE) uses positive inspiratory and negative expiratory pressures to increase peak expiratory flow, simulating a cough. MIE has been shown to facilitate secretion clearance and maintain gas exchange in patients with neuromuscular weakness. The combination of noninvasive ventilation and MIE may be used to avoid permanent tracheostomy and invasive ventilation.

\section{What this paper contributes to our knowledge}

In a heterogeneous series of subjects with neuromuscular disease requiring invasive mechanical ventilation, extubation to noninvasive ventilation and MIE was successful in most subjects. In subjects with an oxygen saturation of $<95 \%$ on room air, MIE improved oxygenation, vital capacity, and secretion clearance.

\section{Methods}

The records of all subjects with NMD who were referred to University Hospital (Newark, New Jersey) for extubation from January 2009 through 2013, that is, following our 2010 report, ${ }^{18}$ were reviewed. The chart review was approved by our institutional review board (review pro2013003890). Inclusion criteria included being willing to be extubated to CNVS despite failing all ventilator weaning parameters including not having "adequate cough, few secretions, ... (or tolerating) a low level of pressure support for a prolonged period without signs of fatigue, $\mathrm{VC}>10 \mathrm{~mL} / \mathrm{kg}$, (or tolerating) T-piece breathing for $>4 \mathrm{~h}$ prior to extubation." 24 In addition, the $\mathrm{S}_{\mathrm{pO}_{2}}$ had to be normalizable $(\geq 95 \%)$ in ambient air with full ventilatory support and aggressive MIE, and subjects had to demonstrate no autonomous breathing ability after extubation by being in immediate distress with rapid oxyhemoglobin desaturation when unsupported. Exclusion criteria were persistent medical instability, lack of cooperation, persistent failure to achieve and maintain $\mathrm{S}_{\mathrm{pO}_{2}}$ of $95 \%$ or greater in ambient air despite MIE and full ventilatory support, or a successful SBT or breathing tolerance without CNVS upon extubation. The number of failed extubation attempts and time using mechanical ventilation were recorded.

All transferred and local subjects were treated the same; however, those arriving from out-of-state were intubated longer because of having failed one or more extubation attempts and having to wait for third-party payers to approve the transfers. All of the transferred subjects had been told by their physicians that tracheotomy was their only 
option for survival, but all refused it and demanded to be transferred for extubation.

At presentation for extubation, end-tidal $\mathrm{CO}_{2}$ or alveolar $\mathrm{P}_{\mathrm{CO}_{2}}$, if elevated, was normalized by increasing ventilator settings and reassigning appropriate physiologic back-up rates. Supplemental oxygen was discontinued. The airways were suctioned, and then the $\mathrm{VC}$ was recorded (first data point). The VC was measured as the exhaled volume with subjects in CPAP mode without pressure support exhaling a maximally inhaled breath with the cuff fully inflated. Cry VCs were measured for children who were unable to cooperate. ${ }^{25}$ Medical and respiratory regimens, including chest physical therapy and use of antibiotics and bronchodilators, were decided by the primary medical teams and remained unchanged.

MIE (CoughAssist, Philips Respironics, Murrysville, Pennsylvania) was then instituted with insufflation and exsufflation pressures of $60-70 \mathrm{~cm} \mathrm{H}_{2} \mathrm{O}$ used via the airway tubes up to every hour while awake until ambient air $\mathrm{S}_{\mathrm{pO}_{2}}$ remained $95 \%$ or greater. For infants and young children, the insufflation and exsufflation cycles were timed to spontaneous breathing. Extubation readiness was determined by reversal of all acute illnesses, being medically stable and afebrile with a normal leukocyte count, and having normal $\mathrm{CO}_{2}$ and $\mathrm{S}_{\mathrm{pO}_{2}}$ of $\geq 95 \%$ in ambient air. ${ }^{18}$ Once achieved, the VC was re-measured (second data point) (Wright Spirometer Mark 8, Grace Medical Marketing, Kennesaw, Georgia), and any indwelling nasogastric or orogastric tubes were removed. The subjects were extubated to mouthpiece or nasal CNVS as they preferred. Adolescents and adults used assist/volume control mode at 700-1,500 $\mathrm{mL}$ volumes, rates $10-12 / \mathrm{min}$, and no PEEP. Small children were placed on assist/pressure control mode, usually at $16-20 \mathrm{~cm} \mathrm{H}_{2} \mathrm{O}$ pressure and age-appropriate back-up rates. Staff and family care providers administered MIE in the critical care unit at $35-60 \mathrm{~cm} \mathrm{H}_{2} \mathrm{O}$ insufflation and exsufflation pressures, the maximum tolerated for full clinical chest expansion and emptying in not so much time as to cause hypoventilation and not so little as to hyperventilate. The MIE was used upon subject demand as well as up to every $30 \mathrm{~min}$ as needed to return and/or maintain ambient air $\mathrm{S}_{\mathrm{pO}_{2}}$ of $95 \%$ or greater. For babies and small uncooperative children, MIE was timed to their breathing. ${ }^{18}$

The hospitalized subjects were discharged home from the ICU or transferred back to out-of-state referring hospitals for discharge home when medically stable with ambient air $\mathrm{S}_{\mathrm{pO}_{2}} \geq 95 \%$ once their care providers were adept at administering NVS and MIE. After discharge, the subjects were re-evaluated once they had weaned to a minimum of hours per day of NVS or within 3 weeks if no weaning was possible, and the $\mathrm{VC}$ was again measured (third data point) along with cough peak flows (CPF) (peak flow meter, Access, Cedar Grove, New Jersey). The three
VC data points were compared by $t$ tests for significant differences $(P<.05)$ and diagnostic group differences analyzed by repeated-measures analysis of variance testing with Bonferroni adjustment for multiple comparisons. Successful extubation and subsequent noninvasive management were defined by not requiring a tracheotomy during the hospitalization or at any time during follow-up, although, for amyotrophic lateral sclerosis (ALS), it might have eventually become necessary for further survival.

\section{Results}

One hundred twenty subjects were evaluated for extubation. Of 72 subjects transferred from other institutions, 3 were excluded; one subject changed his mind about extubation to CNVS and underwent tracheotomy; one had cardiovascular instability, and another with severe bilateral bronchiectasis failed to achieve target $\mathrm{S}_{\mathrm{pO}_{2}}$. The remaining 69 subjects had been intubated for $24.9 \pm 22 \mathrm{~d}$ (range 1-158) and failed $0-6$ extubation attempts before transfer, that is, 29 failed one attempt, 14 failed 2 attempts, 6 failed 3 attempts, and one failed 6 attempts for a mean of 1.7 failures for the 50 having failed one or more attempts. Forty-eight local subjects were intubated at our hospital but 19 were excluded. Eighteen of the 19 subjects passed SBTs and were extubated to low span bi-level PAP or were unaided except for the use of MIE to clear airway secretions. The other subject was excluded because of persistent medical instability. Thus, 98 subjects were enrolled.

We had placed all of the 29 local subjects who satisfied inclusion criteria on NVS. Twenty-one of the 29 were CNVS-dependent for 4 months to $18 \mathrm{y}$ with little or no ventilator-free breathing ability before being intubated for acute respiratory failure. Of the 69 transferred subjects, 23 were unaided before developing ARF and being intubated, 8 had been using bi-level PAP, and we had placed 38 on sleep NVS. Twenty-four of the 38, also including 19 from out-of-state, were CNVS-dependent for 9 months to $17 \mathrm{y}$ before developing ARF and being transferred to us for extubation. Thus, 45 total pre-extubation CNVS users were not candidates to wean post-extubation.

Sixty-three of the 69 transferred subjects (91\%) achieved target ambient air $\mathrm{S}_{\mathrm{pO}_{2}}$ baseline in $1.96 \pm 1.81 \mathrm{~d}$ once MIE was used via the tubes. Thirty-seven of the 69 transferred subjects were extubated in less than $24 \mathrm{~h}$ and the other 32 were extubated in $3.4 \pm 3.4($ range $=2-8)$ d. The 29 local subjects were intubated for $5.1 \pm 3.6 \mathrm{~d}$ before successful extubation.

Eight subjects failed the initial protocol extubation attempt. Six subjects (one with ALS, 4 with spinal muscular atrophy (SMA) type 1, and one with SMA type 3) succeeded on a second attempt; one 8-y-old with a restrictive pulmonary syndrome succeeded on a third attempt, but one bulbar ALS subject underwent tracheotomy after fail- 
InSUfFlation-ExSUfFlation IN CRITICAL CARE

Table 1. Changes in Vital Capacity and Ventilator Dependence Associated With Mechanical Insufflation-Exsufflation

\begin{tabular}{|c|c|c|c|c|c|c|c|c|c|}
\hline \multirow[b]{2}{*}{ Diagnosis } & \multirow[b]{2}{*}{$\begin{array}{l}\text { Subjects } \\
\quad(n)\end{array}$} & \multirow[b]{2}{*}{$\begin{array}{c}\text { Age at } \\
\text { Successful } \\
\text { Extubation (y) }\end{array}$} & \multirow[b]{2}{*}{$\begin{array}{c}\mathrm{CPF} \geq 160, \\
<300 \mathrm{~L} / \mathrm{min} \\
\text { After } \\
\text { Successful } \\
\text { Extubation }\end{array}$} & \multicolumn{3}{|c|}{ Vital Capacity (mL) } & \multicolumn{3}{|c|}{ Post-Extubation } \\
\hline & & & & $\begin{array}{c}\text { At } \\
\text { Admission } \\
\text { (data point } 1 \text { ) }\end{array}$ & $\begin{array}{c}\text { Immediately } \\
\text { Before } \\
\text { Extubation } \\
\text { (data point } 2 \text { ) }\end{array}$ & $\begin{array}{c}\text { Maximum } \\
\text { Within } 3 \mathrm{wk} \\
\text { After Successful } \\
\text { Extubation } \\
\text { (data point 3) }\end{array}$ & $\begin{array}{c}\text { Minimum } \\
\text { NVS Use } \\
\text { Within } 3 \text { wk } \\
\text { (h/d) }\end{array}$ & $\begin{array}{l}\text { CNVS } \\
\text { Dependence } \\
\text { (mo) }\end{array}$ & $\begin{array}{c}\text { Total } \\
\text { NVS/CNVS } \\
\text { Dependence } \\
\text { (mo) }\end{array}$ \\
\hline LS* & 8 & $54.8 \pm 11.5$ & 7 & $\begin{array}{l}(n=7) \\
50 \pm 49\end{array}$ & $\begin{array}{c}(n=7) \\
109 \pm 94\end{array}$ & $\begin{array}{c}(n=7) \\
223 \pm 122\end{array}$ & 24 & $\begin{array}{c}(n=7) \\
12 \pm 9.3\end{array}$ & $\begin{array}{c}(n=7) \\
12 \pm 9.3\end{array}$ \\
\hline DMD & 12 & $23.5 \pm 8.5$ & 11 & $99 \pm 51$ & $6 \pm 63$ & 政 & $18 \pm 8$ & $\begin{array}{c}(n=8) \\
25.7 \pm 33.6\end{array}$ & $\begin{array}{c}(n=12) \\
23.6 \pm 26.4\end{array}$ \\
\hline $\begin{array}{l}\text { Non-DMD muscular } \\
\text { dystrophy }\end{array}$ & 3 & $27.7 \pm 5.7$ & 3 & $223 \pm 71$ & $467 \pm 178$ & $640 \pm 147$ & $16 \pm 8$ & $\begin{array}{c}(n=2) \\
43.0 \pm 5.7\end{array}$ & $\begin{array}{c}(n=3) \\
45.0 \pm 5.2\end{array}$ \\
\hline SMA1 & 26 & $4.5 \pm 5.1$ & 1 & $15 \pm 33$ & $32 \pm 40$ & $67 \pm 63$ & $21 \pm 8$ & $\begin{array}{c}(n=19) \\
27.5 \pm 5.8\end{array}$ & $\begin{array}{c}(n=26) \\
25.2 \pm 5.2\end{array}$ \\
\hline oSMA & 15 & $12.7 \pm 12.5$ & 10 & $145 \pm 139$ & $295 \pm 249$ & $439 \pm 381$ & $9 \pm 4$ & $\begin{array}{c}(n=1) \\
1\end{array}$ & $\begin{array}{c}(n=15) \\
24 \pm 20.9\end{array}$ \\
\hline oNMD & 23 & $32.8 \pm 22.5$ & 19 & $115 \pm 88$ & $225 \pm 148$ & $399 \pm 231$ & $13 \pm 6$ & $\begin{array}{c}(n=6) \\
9.2 \pm 7.9\end{array}$ & $\begin{array}{c}(n=23) \\
20 \pm 23.9\end{array}$ \\
\hline Polio & 2 & $70.5 \pm 10.6$ & 2 & $205 \pm 35$ & $340 \pm 141$ & $855 \pm 431$ & $12 \pm 6$ & 0 & $\begin{array}{c}(n=2) \\
11.5 \pm 10.6\end{array}$ \\
\hline Obesity & 1 & 66 & 1 & 590 & 780 & 820 & 24 & 21 & 21 \\
\hline RPS & 5 & $53 \pm 27.1$ & 3 & $133 \pm 80$ & $227 \pm 115$ & $507 \pm 81$ & 8 & $\begin{array}{c}(n=1) \\
12\end{array}$ & $\begin{array}{c}(n=5) \\
14.7 \pm 4.6\end{array}$ \\
\hline SCI & 3 & $51.3 \pm 23.7$ & 2 & $250 \pm 56$ & $397 \pm 85$ & $657 \pm 143$ & 8 & 0 & $\begin{array}{c}(n=3) \\
22 \pm 32\end{array}$ \\
\hline Total & 98 & $36.0 \pm 21.1$ & 59 & $\begin{array}{c}(n=95) \\
186 \pm 161 \dagger\end{array}$ & $\begin{array}{c}(n=95) \\
303 \pm 215 \dagger+\end{array}$ & $\begin{array}{c}(n=95) \\
491 \pm 251 \ddagger\end{array}$ & $\begin{array}{c}(n=97) \\
13.6 \pm 7.6\end{array}$ & $\begin{array}{c}(n=45) \\
19.0 \pm 24.3\end{array}$ & $\begin{array}{c}(n=97) \\
24.6 \pm 17.3\end{array}$ \\
\hline \multicolumn{10}{|c|}{ 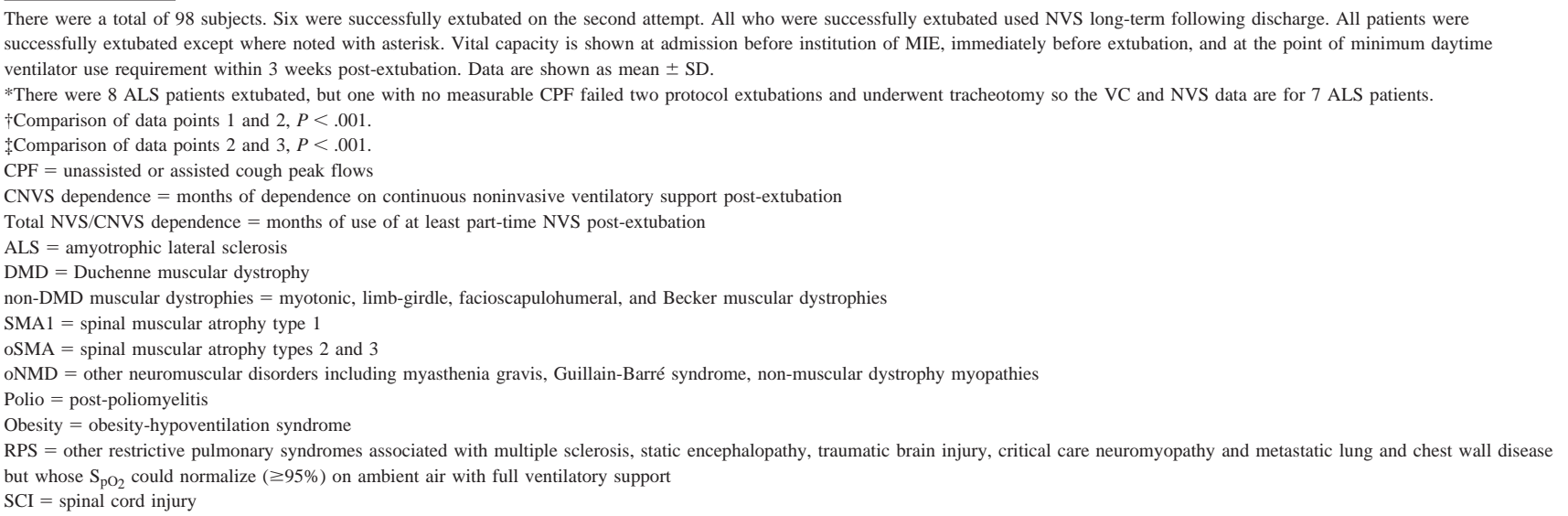 } \\
\hline
\end{tabular}

ing 2 extubation attempts. The initial extubation success rate was $91 \%$. Table 1 presents the diagnoses, CPF after extubation, and the $\mathrm{VC}$ at the 3 data points. Failure to wean and be extubated before transfer persisted for a mean of $24.9 \mathrm{~d}$ for 69 subjects; therefore, the significant improvements achieved in a mean of under $2 \mathrm{~d}$ after transfer, rather than being time-related, were due to a specific intervention scenario. From data point 1 to 2 , the intervention was up to hourly MIE via the translaryngeal tube until $\mathrm{S}_{\mathrm{pO}_{2}}$ normalized. From data point 2 to 3 , home care providers delivered post-extubation MIE via oronasal interface up to every $30 \mathrm{~min}$. In the post hoc analysis, the differences were also significant $(P<.001)$ for the following individual diagnostic groups: ALS, Duchenne muscular dystrophy, non-SMA type 1, other NMD, and miscellaneous including restrictive pulmonary syndromes, as well as $(P=.007)$ for SMA type 1 .

Post-extubation, 52 of the 98 subjects weaned themselves from CNVS to part-time NVS $(13.6 \pm 7.6 \mathrm{~h} / \mathrm{d})$ within $21 \mathrm{~d}$ (Table 1 in which total CNVS dependence time is less than total NVS time). The other 45 subjects, who were unweanable for months before intubation, including 23 under age 5, remained CNVS-dependent. A remarkable case was that of an 8-month-old with SMA 
type 1 who was intubated for $158 \mathrm{~d}$ and failed 6 extubation attempts and then was successfully extubated within $24 \mathrm{~h}$ of transfer and discharged home in 2 weeks once home care services and supplies were available. Nine of the 98 extubated subjects died after an average of 24.6 months (Table 1); 5 with bulbar ALS, one with Duchenne muscular dystrophy, and 3 with other NMDs.

\section{Discussion}

Over the last 30 years, there has been a tendency toward earlier tracheotomy of intubated subjects since the otorhinolaryngology literature reported that intubation could cause laryngeal and vocal cord scarring that could permanently alter speech. ${ }^{26}$ A 3-week time limit was then commonly accepted. However, at the time, the materials used for endotracheal tubes were toxic. ${ }^{27}$ Subsequently, a higher incidence of laryngotracheal stenosis has been reported following tracheotomy of intubated subjects than in either subjects intubated for several weeks or in subjects undergoing tracheotomy without prior intubation. ${ }^{28}$ Thus, it may be preferable to maintain intubation longer in the hope of successful extubation rather than to resort to tracheotomy for selected subjects. ${ }^{28}$ Our study, in which transferred subjects were intubated for over 3 months and even up to 6 months without any untoward clinically apparent effects, is consistent with these findings. Airway damage and obstruction could have rendered MIE flows ineffective in clearing airway secretions such that extubation might have failed. ${ }^{18,29}$

After control of the subject's acute illness, extubation readiness is conventionally tested by SBTs and passing ventilator weaning parameters, but $\mathrm{VC}$ and pre-intubation dependence on NVS are not always considered. Many of the subjects who were CNVS-dependent before intubation were placed on synchronized intermittent mandatory ventilation weaning protocols despite having had little or no ventilator-free breathing ability even before hospitalization and intubation. Indeed, even when ventilator weaning parameters are passed, failure rates for planned extubations are up to $20 \%^{30}$ and are even higher for subjects with NMD, chronic respiratory disorders, and airway obstruction, and for those using prolonged mechanical ventilation. However, in this study, 45 subjects who were unweanable for months to years even before being intubated and who had VCs as low as unmeasurable were successfully extubated. This group of subjects cannot be successfully extubated to supplemental oxygen alone or in combination with CPAP. For such subjects, low spans of bi-level PAP are often inadequate; full ventilator setting NVS is rarely tried ${ }^{31}$; MIE is not considered; and subjects who fail SBTs continue, therefore, to be excluded from extubation studies. ${ }^{30,32-35}$

In our experience, when subjects with NMD develop pneumonia, VC and cough flows plummet and respiratory failure can develop. Supplemental oxygen, rather than CNVS and MIE, is commonly used to normalize $\mathrm{S}_{\mathrm{pO}_{2}}$, thus exacerbating hypercapnia and increasing the need for translaryngeal intubation. Failing weaning parameters and extubation attempts, they conventionally undergo tracheotomy, from which point their care typically costs approximately $\$ 350,000 / y^{15,16}$ or from 3 to 30 times more than for CNVS users. ${ }^{36}$ Thus, a successful noninvasive management program can be highly cost-effective, but it depends on the expertise of a team of both primary and critical care physicians as well as specifically trained home care respiratory therapists.

Currently, third-party payers are approving the provision of mechanical in-exsufflation for patients with NMDs but not for other diagnoses when, in fact, any patient with airway secretions and inadequate cough flows to clear them needs assistance. The diagnoses for which this treatment paradigm is appropriate should be expanded. Although none of the subjects in this study could generate strong unassisted cough flows $(>300 \mathrm{~L} / \mathrm{min})$ immediately postextubation when it was so critical to do so, one subject without NMD was able to do so months later.

Even though CNVS has supported subjects with Duchenne muscular dystrophy, ${ }^{13} \mathrm{SCI},{ }^{19,20}$ post-polio survivors, ${ }^{16}$ and children with SMA type $1^{37}$ for over $20 \mathrm{y}$ and subjects with ALS for up to $8 \mathrm{y},{ }^{38}$ it continues to be grossly underutilized. Indeed, because many CNVS users do not qualify for nursing services, do not benefit from paid attendant services, and are not acceptable to nursing facilities in most states, they are usually managed at home where they want to be and with their quality of life preserved.

Previously, it was felt that CPF less than $160 \mathrm{~L} / \mathrm{min}$ signaled insufficient airway patency, most often due to severe bulbar-innervated muscle dysfunction, that prevents effective use of MIE post-extubation. ${ }^{39}$ However, in this study, 38 of 98 subjects with CPF less than $160 \mathrm{~L} / \mathrm{min}$ and all of the SMA type 1 subjects with absent bulbar function were successfully extubated. Only one subject with CPF greater than $160 \mathrm{~L} / \mathrm{min}$ failed extubation. Therefore, we now realize that it is not the severity of bulbar-innervated muscle dysfunction that prevents successful noninvasive management, but some combination of continuous saliva aspiration and glottic spasticity as seen in ALS but not in SMA type 1 that prevents $\mathrm{S}_{\mathrm{pO}_{2}}$ remaining $\geq 95 \%$ and necessitates tracheotomy for survival.

Although many centers worldwide have reported successfully using MIE via noninvasive interfaces to prevent pneumonia and $\mathrm{ARF},{ }^{40-45}$ only our group ${ }^{19,20,31}$ and one other ${ }^{46}$ have reported its use via tracheostomy tubes. MIE use with intubated subjects had only been described in our 2010 study ${ }^{18}$ and in European subjects with lung disease. ${ }^{14}$ In the $1950 \mathrm{~s}$, the most effective MIE pressures were reported to be $40 \mathrm{~mm} \mathrm{Hg}\left(54 \mathrm{~cm} \mathrm{H}_{2} \mathrm{O}\right){ }^{47-49}$ These are pressures that many clinicians are hesitant to use. However, there is a severe pressure drop-off across invasive 
airway tubes, ${ }^{50,51}$ and we observed no clinically apparent barotrauma during this or our previous studies. ${ }^{19,36-39,42}$ The safety of using MIE is corroborated by considering the $>1,000$ out-patients with NMDs who have air stacked 3 times daily to $80 \mathrm{~cm} \mathrm{H}_{2} \mathrm{O}$ pressures for up to $60 \mathrm{y}$ with no apparent adverse effects. ${ }^{52,53}$

Past studies ${ }^{13,18-21,38,39}$ emphasized the importance of MIE to avoid intubation. This study demonstrates its essential role in increasing $\mathrm{VC}$ and ambient air $\mathrm{S}_{\mathrm{pO}_{2}}$ to improve gas exchange, and permit extubation to CNVS and subsequent partial ventilator weaning. Despite being intubated and without access to MIE for weeks before transfer and having ambient air $\mathrm{S}_{\mathrm{pO}_{2}}$ baselines below $95 \%$, the baselines were expeditiously normalized with only the addition of MIE. Since 1993, we have recognized that, for cooperative subjects with NMD who fail conventional weaning, conversion from invasive to noninvasive ventilation requires maintaining normal alveolar ventilation and oxygenation on ambient air, but these requirements are not essential for subjects without primarily muscle impairment. We consider the key differences between these two populations to be poor or absent ventilatory reserve, high risk of respiratory muscle fatigue, and very limited or absent ability to clear central airway secretions. Inasmuch as desaturation on ambient air indicates some combination of hypoventilation, airway secretion encumbrance, and residual pulmonary disease, maintaining ambient air $\mathrm{S}_{\mathrm{pO}_{2}}$ of 95\% or greater is a high priority criterion for removal of invasive ventilation. In addition, suctioning the pharynx and proximal trachea cannot substitute for the cough flows needed to clear the six central airway divisions. We consider that our success was due to subject selection and MIE use before and after extubation, and extubation to CNVS rather than low span bi-level PAP or CPAP. The use of MIE allowed for continued increases in VC in the weeks after discharge from the hospital.

\section{Conclusions}

Although lack of blinding and controls can be considered limitations of this study, extubation of subjects with no autonomous ability to breathe mandates nothing less than extubation to full ventilatory support and supported airway clearance. Nothing else is ethically relevant. Without these before transfer, earlier conventional management using bronchodilators, airway suctioning, chest physical therapy, and ventilator weaning protocols neither resulted in successful extubation nor in weaning. For almost every case in which the ambient air $\mathrm{S}_{\mathrm{pO}_{2}}$ baseline was less than 95\% upon presentation, aggressive MIE resulted in the immediate expulsion of copious mucopurulent secretions and consequent increases in $\mathrm{VC}$ and $\mathrm{S}_{\mathrm{pO}_{2}}$. Thus, the combination of MIE and CNVS permits the removal of airway tubes and self-weaning for selected subjects who satisfy specific criteria. It behooves the respiratory therapy community to learn how to perform MIE in the critical care setting and to train subjects and families in its optimal use.

\section{REFERENCES}

1. Pingleton SK. Complications of acute respiratory failure. Am Rev Respir Dis 1988;37(6):1463-1493.

2. Korber W, Laier Groeneveld G, Criee CP. Endotracheal complications after long term ventilation: noninvasive ventilation in chronic thoracic diseases as an alternative to tracheostomy. Med Klin 1999;94:45-50.

3. Hedden M, Ersoz CJ, Safar P. Tracheoesophageal fistulas following prolonged artificial ventilation via cuffed tracheostomy tubes. Anesthesiology 1969;31(3):281-289.

4. Malingue S, Prunier F, Egreteau JP. Four cases of tracheoesophageal fistula associated with prolonged ventilation [in French]. Ann Anesthesiol Fr 1978;19(6):539-544.

5. Elpern EH, Scott MG, Petro L, Ries M. Pulmonary aspiration in mechanically ventilated adults with tracheostomies (abstract). Am Rev Respir Dis 1993;147:A409.

6. Deutschman CS, Wilton P, Sinow J, Dibbell D Jr, Konstantinides FN, Cerra FB. Paranasal sinusitis associated with nasotracheal intubation: a frequently unrecognized and treatable source of sepsis. Crit Care Med 1986;14(2):111-114.

7. Moar JJ, Lello GE, Miller SD. Stomal sepsis and fatal haemorrhage following tracheostomy. Int J Oral Maxillofac Surg 1986; 15(3):339-341.

8. Colice GL. Resolution of laryngeal injury following translaryngeal intubation. Am Rev Respir Dis 1992;145(2):361-364.

9. Heffner JE. Timing of tracheotomy in mechanically ventilated patients. Am Rev Respir Dis 1993;147(3):768-771.

10. Castella X, Gilabert J, Torner F. (letter) Chest 1990;98(3):776-777.

11. Richard I, Giraud M, Perrouin-Verbe B, Hiance D, Mauduyt de la Greve I, Mathé JF. Laryngotracheal stenosis after intubation or tracheostomy in patients with neurological disease. Arch Phys Med Rehabil 1996;77(5):493-496.

12. Bach JR, Saporito LR, Shah HR, Sinquee D. Decanulation of patients with severe respiratory muscle insufficiency: efficacy of mechanical insufflation-exsufflation. J Rehabil Med 2014;46(10): 1037-1041.

13. Bach JR, Martinez D. Duchenne muscular dystrophy: prolongation of survival by noninvasive interventions. Respir Care 2011;56(6): 744-750.

14. Gonçalves MR, Honrado T, Winck JC, Paiva JA. Effects of mechanical insufflation-exsufflation in preventing respiratory failure after extubation: a randomized controlled trial. Critical Care 2012;16(2): R48.

15. Bach JR. New Jersey Department of Health and Senior Services: Study of ventilator dependent patient needs in New Jersey, Jun 15, 2005.

16. Bach JR, Intintola P, Alba AS, Holland I. The ventilator-assisted individual: cost analysis of institutionalization versus rehabilitation and in-home management. Chest 1992;101(1):26-30.

17. Bach JR. A comparison of long-term ventilatory support alternatives from the perspective of the patient and care giver. Chest 1993;104(6): 1702-1706.

18. Bach JR, Gonçalves MR, Hamdani I, Winck JC. Extubation of unweanable subjects with neuromuscular weakness: a new management paradigm. Chest 2010;137(5):1033-1039.

19. Bach JR, Alba AS. Noninvasive options for ventilatory support of the traumatic high level quadriplegic. Chest 1990;98(3):613-619.

20. Bach JR. New approaches in the rehabilitation of the traumatic high level quadriplegic. Am J Phys Med Rehabil 1991;70(1):13-20.

21. Bach JR, Gonçalves M. Ventilator weaning by lung expansion and decanulation. Am J Phys Med Rehabil 2004;83(7):560-568. 
22. Barach AL, Beck GJ. Exsufflation with negative pressure: physiologic and clinical studies in poliomyelitis, bronchial asthma, pulmonary emphysema and bronchiectasis. Arch Int Med 1954;93(6):825-841.

23. Bach JR. Mechanical insufflation-exsufflation: comparison of peak expiratory flows with manually assisted and unassisted coughing techniques. Chest 1993;104(5):1553-1562.

24. Mehta S. Neuromuscular disease causing acute respiratory failure. Respir Care 2006;51(9):1016-1021; discussion 1021-1023.

25. Chiswick ML, Milner RD. Crying vital capacity: measurement of neonatal lung function. Arch Dis Child 1976;51(1):22-27.

26. Colice GL. Resolution of laryngeal injury following translaryngeal intubation. Am Rev Respir Dis 1992;145(2 Pt 1):361-364.

27. Reynolds LA, Tansey EM. History of British intensive care c. 1950c. 2000: transcript of a witness seminar held by the Wellcome Trust Centre for the History of Medicine at University College London, The Wellcome Trust, on 16 Jun 2010.

28. Richard I, Giraud M, Perrouin-Verbe B, Hiance D, Mauduyt de la Greve I, Mathé JF. Laryngotracheal stenosis after intubation or tracheostomy in subjects with neurological disease. Arch Phys Med Rehabil 1996;77(5):493-496.

29. Bach JR, Saporito LR. Indications and criteria for decannulation and transition from invasive to noninvasive long term ventilatory support. Respir Care 1994;39(5):515-528; discussion 529-531.

30. Frutos-Vivar F, Ferguson ND, Esteban A, Epstein SK, Arabi Y, Apezteguía C, et al. Risk factors for extubation failure in subjects following a successful spontaneous breathing trial. Chest 2006;130(6): 1664-1671.

31. Bach JR, Gonçalves MR, Hon A, Ishikawa Y, De Vito EL, Prado F, Dominguez ME. Changing trends in the management of end-stage respiratory muscle failure in neuromuscular disease: current recommendations of an international consensus. Am J Phys Med Rehabil 2013;92(3):267-277.

32. Ferrer M, Valencia M, Nicolas JM, Bernadich O, Badia JR, Torres A. Early noninvasive ventilation averts extubation failure in subjects at risk: a randomized trial. Am J Respir Crit Care Med 2006;173(2): 164-170.

33. Templeton M, Palazzo MG. Chest physiotherapy prolongs duration of ventilation in the critically ill ventilated for more than 48 hours. Intensive Care Med 2007;33(11):1938-1945.

34. Burns KE, Adhikari NK, Keenan SP, Meade M. Use of non-invasive ventilation to wean critically ill adults off invasive ventilation: metaanalysis and systematic review. BMJ 2009;338:b1574-b1580.

35. Nava S, Ambrosino N, Clini E, Prato M, Orlando G, Vitacca M, Brigada P, Fracchia C, Rubini F. Noninvasive mechanical ventilation in the weaning of subjects with respiratory failure due to chronic obstructive pulmonary disease: a randomized, controlled trial. Ann Intern Med 1998;128(9):721-728.

36. Bach JR, Tran J, Durante S. Cost and physician effort analysis of invasive vs. noninvasive respiratory management of Duchenne muscular dystrophy. Am J Phys Med Rehabil 2014; in press.

37. Bach JR, Gupta K, Reyna M, Hon A. Spinal muscular atrophy type 1: prolongation of survival by noninvasive respiratory aids. Pediatr Asthma Allergy Immunol 2009;22(4):151-162.
38. Bach JR, Bianchi C, Aufiero E. Oximetry and indications for tracheotomy in amyotrophic lateral sclerosis. Chest 2004;126(5):15021507.

39. Bach JR, Saporito LR. Criteria for extubation and tracheostomy tube removal for subjects with ventilatory failure: a different approach to weaning. Chest 1996;110(6):1566-1571.

40. Chatwin M, Ross E, Hart N, Nickol AH, Polkey MI, Simonds AK. Cough augmentation with mechanical insufflation/exsufflation in subjects with neuromuscular weakness. Eur Respir J 2003;21(3):502508.

41. Sivasothy P, Brown L, Smith IE, Shneerson JM. Effect of manually assisted cough and mechanical insufflation on cough flow of normal subjects, subjects with chronic obstructive pulmonary disease (COPD), and subjects with respiratory muscle weakeness. Thorax 2001;56(6):438-444.

42. Gómez-Merino E, Sancho J, Marín J, Servera E, Blasco ML, Belda FJ, Castro C, Bach JR. Mechanical insufflation-exsufflation: pressure, volume, and flow relationships and the adequacy of the manufacturer's guidelines. Am J Phys Med Rehabil 2002;81(8):579-583.

43. Miske LJ, Hickey EM, Kolb SM, Weiner DJ, Panitch HB. Use of the mechanical in-exsufflator in pediatric subjects with neuromuscular disease and impaired cough. Chest 2004;125(4):1406-1412.

44. Sancho J, Servera E, Díaz J, Marín J. Efficacy of mechanical insufflation-exsufflation in medically stable subjects with amyotrophic lateral sclerosis. Chest 2004;125(4):1400-1405.

45. McKim DA, Katz SL, Barrowman N, Ni A, LeBlanc C. Lung volume recruitment slows pulmonary function decline in Duchenne muscular dystrophy Arch Phys Med Rehabil 2012;93(7):1117-1122.

46. Sancho J, Servera E, Vergara P, Marín J. Mechanical insufflationexsufflation vs. tracheal suctioning via tracheostomy tubes for subjects with amyotrophic lateral sclerosis: a pilot study. Am J Phys Med Rehabil 2003;82(10):750-753.

47. Barach AL, Beck GJ. Mechanical production of expiratory flow rates surpassing the capacity of human coughing. Am J Med Sci 1953; 226(3):241-249.

48. Beck GJ, Barach AL. Value of mechanical aids in the management of a patient with poliomyelitis. Ann Int Med 1954;40(6):1081-1094.

49. Beck GJ, Graham GC, Barach AL. Effect of physical methods on the mechanics of breathing in poliomyelitis. Ann Intern Med 1955;43(3): 549-566.

50. Toussaint M. The use of mechanical insufflation-exsufflation via artificial airways. Respir Care 2011;56(8):1217-1219.

51. Guérin C, Bourdin G, Leray V, Delannoy B, Bayle F, Germain M, Richard JC. Performance of the CoughAssist insufflation-exsufflation device in the presence of an endotracheal tube or tracheostomy tube: a bench study. Respir Care 2011;56(8):1108-1114.

52. Kang SW, Bach JR. Maximum insufflation capacity. Chest 2000; 118(1):61-65.

53. Bach JR. Respiratory muscle aids: patient evaluation, respiratory aid protocol, and outcomes. In: Bach JR, editor. The management of subjects with neuromuscular disease. Philadelphia: Hanley \& Belfus;2004:271-308.

This article is approved for Continuing Respiratory Care Education credit. For information and to obtain your CRCE

(free to AARC members) visit

www.rcjournal.com

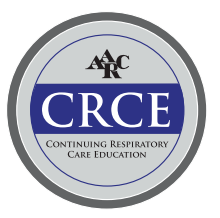

